\title{
Predição de desempenho com uso de sistemas de exigências nutricionais e características de carcaça de tourinhos zebuínos
}

\author{
Julimar do Sacramento Ribeiro(1), Márcio Machado Ladeira( ${ }^{(1)}$, Tarcisio de Moraes Gonçalves(1), \\ Marcelo Alcântara Whately ${ }^{(1)}$ e Marcelo Silva Bassi ${ }^{(1)}$
}

\begin{abstract}
(1)UniversidadeFederal de Lavras, Departamento deZootecnia, CaixaPostal3037,CEP37200-000Lavras, MG.E-mail:julimarzoo@hotmail.com, mladeira@ufla.br, tarcisio@ufla.br, marcelowhately@hotmail.com, mclbassi@yahoo.com.br
\end{abstract}

\begin{abstract}
Resumo - O objetivo deste trabalho foi avaliar a predição de desempenho pelos sistemas CNCPS 5.0, NRC 2000 e BR-CORTE, bem como o ganho de peso diário (GPD) e as características de carcaça em tourinhos zebuínos. Foram utilizados 44 tourinhos: 19 Nelore PO, 7 Nelore LA, 10 Tabapuã PO e 8 Guzerá PO, com peso corporal médio inicial de 266, 236, 222 e $219 \mathrm{~kg}$ e idade inicial média de 9, 10, 8 e 8 meses, respectivamente. O período experimental foi de 112 dias. O consumo alimentar individual foi obtido com o uso de indicadores (LIPE, óxido crômico e FDAi). Informações sobre área de olho de lombo (AOL), espessura de gordura subcutânea (EGS) e espessura de gordura na garupa (P8) foram obtidas por ultrassonografia. Para comparação do GPD predito e observado, foi utilizada análise de regressão linear. Os valores de GPD, AOL, EGS e P8 não diferiram entre os grupos genéticos. Para os sistemas CNCPS 5.0 e NRC 2000, os menores valores de GPD preditos foram estimados com base na disponibilidade de energia; para BR-CORTE, foram baseados na disponibilidade de proteína. Os sistemas NRC 2000, CNCPS 5.0 e BR-CORTE superestimaram o GPD, e não se mostraram adequados para predição do desempenho de tourinhos zebuínos.
\end{abstract}

Termos para indexação: Bos taurus indicus, Guzerá, indicadores, Nelore, Tabapuã, ultrassonografia.

\section{Performance prediction using nutritional systems and carcass traits of young Zebu bulls}

\begin{abstract}
The objective of this work was to evaluate the performance prediction by the CNCPS 5.0, NRC 2000 and BR-CORTE systems, as well as the average daily weight gain (ADG) and the carcass traits of young Zebu bulls. Fourty-four young bulls were used: 19 Nelore PO, 7 Nelore OB, 10 Tabapuã PO and 8 Guzerat PO, with initial body weight of 266, 236, 222 and $219 \mathrm{~kg}$ and initial average age of 9, 10, 8 and 8 months respectively. The experimental period was of 112 days. The individual intake was measured using markers (LIPE, chromic oxide and indigestible acid detergent fiber). The data on rib-eye area (REA), subcutaneous fat thickness (SFT) and rump fat thickness (P8) were obtained using ultrasonography. For the comparison of the estimated and observed ADG values, linear regression analysis was used. ADG, REA, SFT and P8 did not differ amongst the genetic groups. For the CNCPS 5.0 and NRC 2000 systems, the lowest ADG values predicted were estimated based on the available energy; for BR-CORTE, the lowest values were estimated based on available protein. The NRC 2000, CNCPS 5.0 and BR-CORTE systems overestimated the ADG, and were inadequate for predicting the performance of young Zebu bulls.
\end{abstract}

Index terms: Bos taurus indicus, Guzerat, markers, Nelore, Tabapuã, ultrasonography.

\section{Introdução}

Aproximadamente $80 \%$ do rebanho bovino nacional é composto por animais zebuínos e seus mestiços (Valadares Filho et al., 2006b). Assim, estudos sobre desempenho e características de carcaça das raças zebuínas representam importante subsídio para a melhoria na produção da pecuária brasileira. Esses estudos também podem propiciar a criação de planos nutricionais compatíveis com esses grupos genéticos, e podem servir para estabelecer idade e peso de abate que proporcionem maior eficiência de ganho de peso e de características desejáveis de carcaça (Jorge et al., 1997).

O monitoramento de características de carcaça in vivo, tais como a área de olho de lombo (AOL) e a espessura de gordura subcutânea (EGS) no músculo longissimus dorsi, auxilia a escolha dos animais a serem abatidos - com mínimo de $3 \mathrm{~mm}$ de EGS - e também fornece informações úteis para incorporação em modelos de crescimento e seleção animal (Bergen et al., 1996). 
A curva de crescimento e, consequentemente, o desempenho dos animais são tratados de diferentes formas pelos variados sistemas de exigências nutricionais, o que pode ocasionar diferentes estimativas de desempenho e de consumo de alimentos. Entre os principais sistemas de exigências nutricionais, que também são utilizados para a avaliação de dietas no Brasil, destacam-se o Nutrient Resource Council 2000 (NRC 2000) (National Research Council, 2000), o Cornell Net Carbohydrate and Protein System (CNCPS 5.0) (Fox et al., 2003) e as Exigências Nutricionais de Zebuínos e Tabelas de Composição de Alimentos (BR-CORTE) (Valadares Filho et al., 2006b).

Destes, apenas o BR-CORTE apresenta em seu banco de dados informações de animais, alimentos e manejo condizentes com as condições brasileiras, pois o NRC 2000 e o CNCPS 5.0 foram desenvolvidos em países de clima temperado e com animais de raças taurinas. Portanto, torna-se necessário avaliar esses sistemas com a finalidade de definir aquele com maior precisão nas predições do desempenho animal em condições nacionais.

$\mathrm{O}$ objetivo deste trabalho foi avaliar a predição de desempenho fornecida pelos sistemas CNCPS 5.0, NRC 2000 e BR-CORTE, o ganho de peso diário (GPD) médio e as características de carcaça em animais Nelore livro aberto (LA), Nelore puro de origem (PO), Tabapuã PO e Guzerá PO.

\section{Material e Métodos}

O experimento foi conduzido no Centro de Avaliação de Desempenho de Ruminantes do Departamento de Zootecnia da Universidade Federal de Lavras $\left(21^{\circ} 14^{\prime} \mathrm{S}\right.$, $45^{\circ} \mathrm{W}$, altitude de $918,84 \mathrm{~m}$ ), entre agosto e novembro de 2006. Foram utilizados 44 tourinhos de 4 grupos genéticos, 19 Nelore PO, 7 Nelore LA, 10 Tabapuã PO e 8 Guzerá PO, com peso corporal inicial médio de $266 \pm 38,236 \pm 31,222 \pm 17$ e $219 \pm 25 \mathrm{~kg}$, respectivamente, e idade inicial média de $9 \pm 1,10 \pm 0,7$, $8 \pm 0,8$ e $8 \pm 1$ meses, respectivamente, oriundos de diferentes rebanhos mantidos em pasto.

O período experimental foi composto por quatro períodos de 28 dias cada um. No início do experimento, os animais foram pesados, após jejum alimentar de 16 horas, e tratados contra ecto e endoparasitas. Durante a adaptação, que correspondeu aos dois primeiros períodos de 28 dias, os tourinhos foram alimentados à vontade com a mesma dieta do período experimental.

A dieta foi formulada de acordo com o NRC 2000, com o objetivo de obter ganho de peso diário de $1,34 \mathrm{~kg} \mathrm{dia}^{-1}$. O volumoso utilizado foi silagem de milho, e a relação volumoso:concentrado mantida foi de 30:70 (Tabela 1).

As baias eram coletivas com espaço de $30 \mathrm{~m}^{2}$ por animal, piso de chão batido, declividade em torno de $8 \%$, área próxima ao comedouro concretada e divisórias em arame liso. Os bebedouros coletivos localizavam-se na divisória de duas baias, e o comedouro utilizado foi do tipo vinilona, descoberto e disposto transversalmente na parte superior do curralete, com $70 \mathrm{~cm}$ lineares para cada animal.

A dieta, em forma de ração total misturada, foi fornecida à vontade aos animais às 8 e $15 \mathrm{~h}$. As sobras foram coletadas na manhã seguinte e a quantidade de ração fornecida foi ajustada a cada dia, para permitir sobras de, no mínimo, $5 \%$.

Com os valores da dieta fornecida e das sobras coletadas diariamente, ambas em $\mathrm{kg} \mathrm{dia}^{-1}$, o valor médio do consumo de matéria seca (CMS) para os 112 dias experimentais foi obtido dividindo-se a diferença entre o fornecido e as sobras diárias pelo número total de animais.

Para a estimativa da produção fecal, foi utilizado o indicador LIPE (lignina purificada e enriquecida),

Tabela 1. Composição percentual de ingredientes e bromatológica da dieta fornecida a novilhos zebuínos confinados.

\begin{tabular}{lc}
\hline Ingrediente & Composição (\%MS) \\
\hline Silagem de milho & 30,0 \\
Milho integral moído & 25,2 \\
Polpa cítrica & 25,2 \\
Farelo de soja & 16,1 \\
Fosfato bicálcico & 0,5 \\
Bicarbonato de sódio & 0,9 \\
Núcleo mineral $^{(1)}$ & 2,1 \\
\hline Nutrientes & \\
\hline Matéria seca (MS) & 71,7 \\
Proteína bruta (PB) $^{(2)}$ & 13,0 \\
Fibra em detergente neutro (FDN) $^{(2)}$ & 33,2 \\
$\mathrm{CNF}^{(2)}$ & 48,0 \\
$\mathrm{EE}^{(2)}$ & 3,3 \\
$\mathrm{NDT}^{(2,3)}$ & 72,0 \\
\hline
\end{tabular}

${ }^{(1)}$ Níveis de garantia por quilograma do produto: Ca, $235 \mathrm{~g}$; P, $45 \mathrm{~g}$; $\mathrm{S}, 23 \mathrm{~g}$; Na, 80,18 g; Zn, 2,38 mg; Cu, $625 \mathrm{mg}$; Fe, 1,18 mg; Mn, $312 \mathrm{mg}$; Co, $32 \mathrm{mg}$; I, 41,6 mg; Se, 11,25 mg; vit. A, $70.000 \mathrm{UI}$; vit. D3, $5.000 \mathrm{UI}$; vit. E, $15 \mathrm{UI}$; niacina, $3,33 \mathrm{mg}$. (2)\% na matéria seca. ${ }^{(3)}$ Calculado segundo o National Research Council (2001). 
em posologia de uma cápsula de $0,5 \mathrm{~g} \mathrm{dia}^{-1}$ por animal (Saliba, 2005), colocada diretamente no esôfago dos animais durante os dias 24,25 e 26 de cada um dos dois últimos períodos experimentais.

O CMS do concentrado foi determinado com uso de óxido crômico misturado ao concentrado, e posteriormente à dieta, na proporção de $10 \mathrm{~g} \mathrm{dia}^{-1}$ por animal, e fornecido aos animais entre o 17 o e o 27 dia dos períodos 3 e 4, com sete dias de adaptação e três dias de coleta (Valadares Filho et al., 2006a).

$\mathrm{Na}$ determinação do CMS do volumoso nos dois últimos períodos, foi utilizada a fibra em detergente ácido indigestível (FDAi) obtida após incubação in situ por 144 horas, de acordo com a técnica descrita por Marais (2000).

A coleta de fezes foi realizada nos animais devidamente contidos em tronco de contenção, de acordo com o seguinte procedimento: às $10 \mathrm{e} 18 \mathrm{~h}$ do dia 25 , às 8 e 16 h do dia 26 e às 6 e 14 h do dia 27 . As amostras foram homogeneizadas a fim de obter uma amostra composta por animal, para análise de todos os indicadores.

A cada 14 dias foram coletadas amostras dos ingredientes do concentrado, do concentrado e da silagem, para análises de matéria seca (MS), matéria orgânica $(\mathrm{MO})$, proteína bruta $(\mathrm{PB})$, fibra em detergente neutro corrigida para cinzas e proteína (FDNcp) e extrato etéreo (EE), segundo Silva \& Queiroz (2002).

Os carboidratos não fibrosos (CNF) foram calculados por meio da equação:

$\mathrm{CNF}=100-(\% \mathrm{~PB}+\% \mathrm{FDNcp}+\% \mathrm{EE}+\%$ cinzas $)$.

A composição bromatológica dos ingredientes da dieta está apresentada na Tabela 2. As frações

Tabela 2. Teores de matéria seca (MS), matéria orgânica (MO), proteína bruta (PB), fibra em detergente neutro corrigido para cinzas e proteína (FDNcp), carboidratos não fibrosos (CNF) e extrato etéreo (EE) da silagem de milho e dos ingredientes do concentrado utilizado na dieta.

\begin{tabular}{lccrr}
\hline Nutriente & $\begin{array}{c}\text { Silagem } \\
\text { de milho }\end{array}$ & $\begin{array}{c}\text { Milho integral } \\
\text { moído }\end{array}$ & $\begin{array}{r}\text { Polpa } \\
\text { cítrica }\end{array}$ & $\begin{array}{r}\text { Farelo } \\
\text { de soja }\end{array}$ \\
\hline MS (\%) & 27,87 & 90,50 & 87,43 & 91,94 \\
MO (\% na MS) & 94,57 & 98,75 & 94,10 & 93,87 \\
PB (\% na MS) & 6,09 & 8,55 & 6,70 & 48,52 \\
FDNcp (\% na MS) & 55,73 & 13,78 & 18,79 & 15,54 \\
CNF (\% na MS) & 29,45 & 71,82 & 63,55 & 27,78 \\
EE (\% na MS) & 3,30 & 4,60 & 3,36 & 2,03 \\
\hline
\end{tabular}

de proteína e carboidratos utilizadas pelo sistema CNCPS 5.0 foram obtidas do banco de dados da Tabela Brasileira de Composição de Alimentos para Bovinos (Valadares Filho et al., 2006b).

As informações de área de olho de lombo (AOL), espessura de gordura subcutânea (EGS) e espessura de gordura na garupa (P8) foram determinadas nos animais vivos, por meio de aparelho de ultrassom Aloka 500V (Corometrics Medical System, Wallingford, CT, EUA) com transdutor linear de 3,5 MHz. As imagens utilizadas para mensuração da AOL e espessura de gordura foram tomadas entre a $12^{\mathrm{a}}$ e $13^{\mathrm{a}}$ costelas. A espessura de gordura na garupa (P8) foi mensurada na junção dos músculos biceps femoris e gluteus medium, entre o ísquio e o íleo, paralelo à vértebra, como descrito por Greiner et al. (2003).

As imagens foram capturadas por meio de um sistema de captura de imagem (Blackbox, Biotronics Inc., Ames, IA, EUA) e digitalizadas e armazenadas por meio do programa Image-J (National Institutes of Health, EUA).

Para a entrada dos dados de cada animal nos sistemas CNCPS 5.0 e NRC 2000, foram adotados: peso à maturidade, $540 \mathrm{~kg}$ (National Research Council, 2000; Silva et al., 2002; Gesualdi Junior et al., 2005); condição corporal, 6, segundo escala de 1 a 9 (Nicholson \& Butterworth, 1986); temperatura de $24^{\circ} \mathrm{C}$; umidade relativa de $50 \%$; estes últimos são os dados médios para a região no período (Estação Climatológica Principal de Lavras/INMET).

De acordo com esses parâmetros estipulados, juntamente com o peso médio dos animais no período e a dieta ingerida, foi feita a predição de ganho de peso em função da energia e proteína disponíveis, por meio dos programas computacionais específicos de cada sistema avaliado. Para se obter o GPD predito com o uso do BR-CORTE, foram utilizadas as equações apresentadas por Valadares Filho et al. (2006b).

Os valores preditos pelos sistemas NRC 2000, CNCPS 5.0 e BR-CORTE foram comparados com os observados por meio de análise de regressão linear (Kobayashi \& Salam, 2000) com uso do PROC GLM do pacote estatístico SAS Institute (1999). O peso inicial foi considerado como covariável e o teste Scott \& Knott foi utilizado para a comparação entre médias, a $5 \%$ de probabilidade. De acordo com a hipótese de nulidade, os valores preditos foram considerados estatisticamente iguais aos observados 
se o intercepto e o coeficiente de inclinação eram iguais a zero e um, respectivamente.

\section{Resultados e Discussão}

Não houve diferença entre os grupos genéticos zebuínos avaliados quanto às características GPD, AOL, EGS e P8 (Tabela 3). Durante os 112 dias do experimento, o CMS médio diário observado foi de $8,91 \mathrm{~kg}$ por dia por animal, resultando em uma eficiência alimentar de 0,118 , uma vez que o GPD médio dos grupos genéticos foi de $1,05 \mathrm{~kg} \mathrm{dia}^{-1}$. O menor ganho de peso observado $\left(1,05 \mathrm{~kg} \mathrm{dia}^{-1}\right)$ em relação ao desejado $\left(1,34 \mathrm{~kg} \mathrm{dia}^{-1}\right)$ provavelmente decorre darelaçãovolumoso:concentrado (30:70), pois, de acordo com Véras et al. (2001), animais zebuínos que recebem elevados teores de concentrado na dieta aumentam a deposição de gordura na carcaça, o que é comprovado pelos altos valores de EGS e P8 para animais dessa idade.

As condições deste experimento demonstraram que todas as raças zebuínas estudadas têm o mesmo desempenho (Tabela 3). Portanto, a escolha do genótipo em um sistema de produção é dependente de fatores como disponibilidade de animais, aceitação de animais descartados, preço de reprodutores entre outros, e não somente do potencial produtivo da raça.

A ausência de diferença significativa nas características AOL, EGS e P8 indicou que os animais provavelmente tinham exigências nutricionais parecidas, com composição corporal semelhante, e não apresentavam precocidade de acabamento diferenciada entre as raças. Cabe ressaltar que os valores de EGS aos 14,6 meses de idade e peso final médio de $418 \mathrm{~kg}$, ou seja, antes que os animais alcançassem o peso mínimo de abate de $450 \mathrm{~kg}$, foram condizentes com os exigidos pelos frigoríficos. Sendo assim, foi constatado neste experimento que a ineficiência de zebuínos em depositar gordura na verdade está relacionada a planos nutricionais não adequados para que os animais atinjam tais objetivos.

Zebuínos têm exigência de mantença menor (National Research Council, 2000; Valadares Filho et al., 2006b) e a densidade energética da dieta, devido ao teor de NDT e à relação entre volumoso e concentrado, possivelmente pode explicar a precocidade no acabamento (deposição de gordura) observada em todos os grupos de animais neste trabalho. Além disso, esse comportamento pode estar relacionado com a forma de partição de energia, pois animais zebuínos tendem a ter menor turnover proteico (Sainz et al., 2006), o que propicia quantidade maior de energia que poderá ser depositada em forma de tecido adiposo. Esse menor turnover proteico e a quantidade de proteína disponível na dieta para ganho, demonstrados pelas predições de ganho de peso dos sistemas de exigências, possibilitam concluir que a proteína não foi fator limitante para o ganho de peso dos animais.

Não houve interação entre grupos genéticos e sistemas ( $p>0,05)$, o que fez com que os dados fossem analisados de forma agrupada, sem distinção de grupo genético. Na Figura 1, bem como na Tabela 4, são apresentadas as regressões lineares entre os valores de ganho de peso observados e os preditos pelos sistemas BR-CORTE, CNCPS 5.0 e NRC 2000, respectivamente.

Para todos os sistemas avaliados, houve rejeição da hipótese de nulidade, ou seja, o intercepto foi diferente de 0 e a inclinação, diferente de 1 . Dessa forma, os valores preditos pelos sistemas de exigências nutricionais diferiram estatisticamente dos valores observados.

Tabela 3. Média dos quadrados mínimos e respectivo erro padrão (EP) do peso corporal inicial (PCI), após 56 dias de adaptação, do peso final, do ganho de peso diário (GPD), da espessura de gordura subcutânea (EGS), da área de olho de lombo (AOL) e da espessura de gordura na garupa (P8), de grupos genéticos zebuínos confinados ${ }^{(1)}$.

\begin{tabular}{|c|c|c|c|c|c|c|c|c|c|}
\hline \multirow[t]{2}{*}{ Variável } & \multicolumn{9}{|c|}{ Grupo genético } \\
\hline & Nelore PO & EP & Nelore LA & EP & Tabapuã & EP & Guzerá & EP & $\mathrm{p}^{(2)}$ \\
\hline PCI (kg) & 302 & 3,65 & 292 & 5,40 & 298 & 4,72 & 298 & 5,30 & 0,50 \\
\hline Peso final $(\mathrm{kg})$ & 421 & 3,94 & 415 & 5,83 & 417 & 5,03 & 415 & 5,63 & 0,83 \\
\hline GPD $\left(\mathrm{kg} \mathrm{dia}^{-1}\right)$ & 1,08 & 0,03 & 1,04 & 0,05 & 1,06 & 0,04 & 1,04 & 0,05 & 0,90 \\
\hline $\operatorname{AOL}\left(\mathrm{cm}^{2}\right)$ & 78,5 & 2,45 & 75,8 & 3,92 & 76,2 & 3,28 & 80,7 & 3,67 & 0,74 \\
\hline EGS (mm) & 5,0 & 0,29 & 4,4 & 0,47 & 4,8 & 0,39 & 3,9 & 0,44 & 0,24 \\
\hline P8 (mm) & 6,3 & 0,33 & 5,5 & 0,53 & 7,0 & 0,47 & 6,8 & 0,50 & 0,15 \\
\hline
\end{tabular}

(1)Médias seguidas de letras iguais nas linhas não diferem entre si pelo teste Scott-Knott, a 5\% de probabilidade. ${ }^{(2)}$ Valor de probabilidade. 

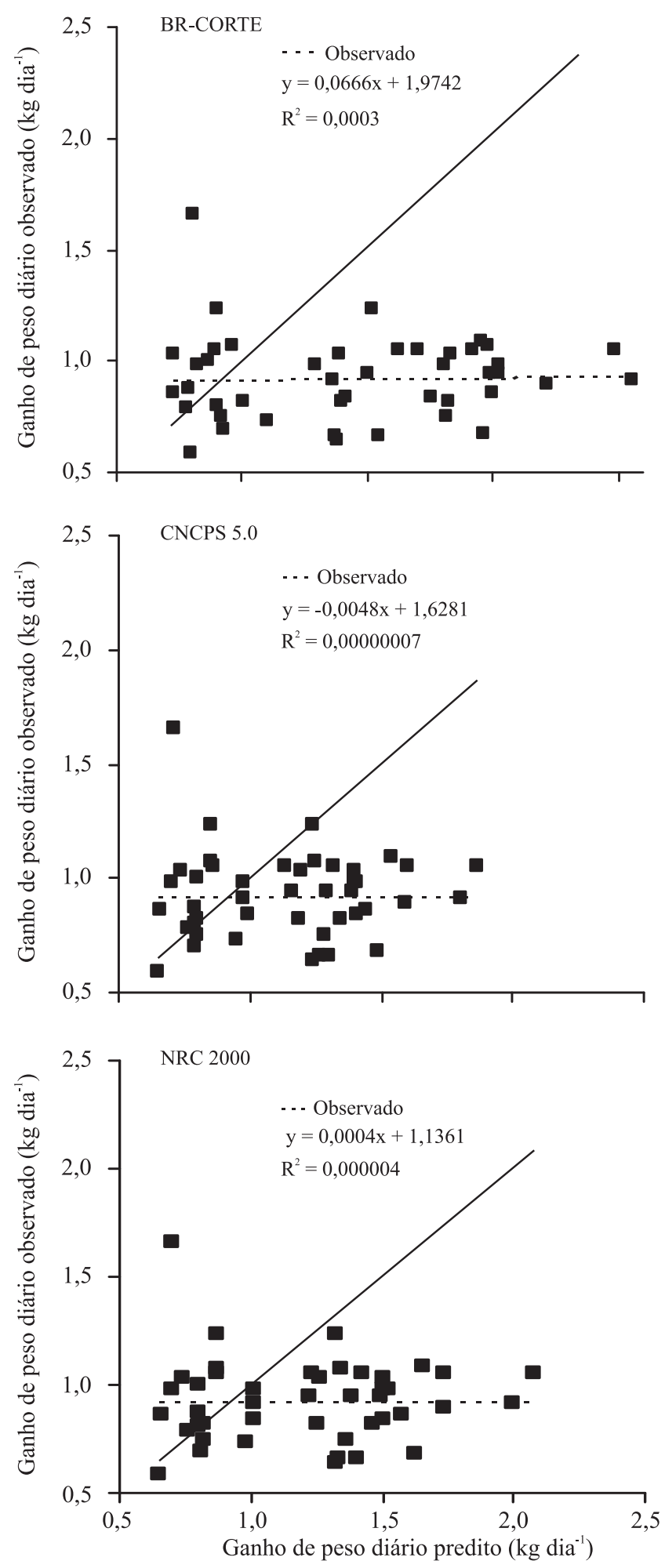

Figura 1. Ganho de peso diário observado versus ganho de peso predito pelo sistema BR-CORTE com base na proteína disponível e pelos sistemas CNPCS 5.0 e NRC 2000 com base na energia disponível. A linha contínua representa valores da reta de equidade $(\mathrm{Y}=\mathrm{X})$; pontos e linha tracejada representam a relação obtida entre os valores observados e preditos.
Nos sistemas CNCPS 5.0 e NRC 2000, os menores valores de ganho de peso foram preditos com base na disponibilidade de energia, enquanto para o sistema BR-CORTE, os menores ganhos preditos foram baseados na disponibilidade de proteína da dieta. Por esse motivo, para os sistemas NRC 2000 e CNCPS 5.0 foram apresentados os dados de desempenho referentes somente à energia e, para o sistema BR-CORTE, os dados referentes somente à proteína. Essa inversão nos valores de predição de desempenho deve-se, basicamente, ao fato de que o sistema BR-CORTE considera uma necessidade de energia líquida para mantença $20 \%$ menor para zebuínos do que para taurinos. Para os sistemas americanos, a exigência energética de mantença é apenas $10 \%$ menor para zebuínos. Dessa forma, a dieta consumida promoveria maior disponibilidade de energia para ganho, segundo o BR-CORTE.

Nenhum dos sistemas estimou com precisão o desempenho com base na energia e na proteína disponível (Tabela 5). De fato, observa-se que todos os sistemas apresentaram predições de ganho de peso elevadas, com valores médios superestimados em 56, 23 e 30\% pelo BR-CORTE, CNCPS 5.0 e NRC 2000, respectivamente.

Devido aos diversos fatores - raça, nível nutricional, sistemas de produção, condição de manejo entre outros passíveis de influência sobre os sistemas de exigências nutricionais, observa-se, na literatura, inconsistência dos dados de desempenho preditos em relação aos observados (Patterson et al., 2000; Block et al., 2006; Gesualdi Júnior et al., 2006). Isso faz com que, independentemente dos resultados, os dados obtidos pelos referidos sistemas sejam analisados com cautela, sendo considerados apenas como indicadores de prováveis resultados segundo as condições estabelecidas.

Tabela 4. Análise de regressão dos valores de ganho de peso diário e erro padrão (EP) observados e preditos pelos sistemas BR-CORTE, CNCPS 5.0 e NRC 2000.

\begin{tabular}{lcrc}
\hline Parâmetro & BR-CORTE & CNCPS 5.0 & NRC 2000 \\
\hline $\mathrm{R}_{\mathrm{a}}^{2}$ & $-0,0233$ & $-0,0237$ & $-0,0238$ \\
\hline \multicolumn{4}{c}{ Inclinação } \\
Valor & 0,0666 & $-0,0048$ & 0,0004 \\
$\mathrm{EP}$ & 0,4570 & 0,3370 & 0,2610 \\
$\mathrm{p}^{(1)}$ & 0,0475 & 0,0049 & 0,0004 \\
\hline \multicolumn{4}{c}{ Intercepto } \\
Valor & 1,9742 & 1,6281 & 1,1361 \\
$\mathrm{EP}$ & 0,4320 & 0,3190 & 0,2460 \\
$\mathrm{p}^{(2)}$ & 0,0001 & 0,0001 & 0,0001 \\
\hline
\end{tabular}

${ }^{(1)}$ Probabilidade de a inclinação ser igual a um. ${ }^{(2)}$ Probabilidade de o intercepto ser igual a zero. $\mathrm{R}^{2}$, coeficiente de determinação ajustado. 
Tabela 5. Valores mínimos, médios e máximos de ganho de peso diário (GPD) observados nos dois últimos períodos experimentais, e valores preditos pelas equações do BR-CORTE, CNCPS 5.0 e NRC 2000 obtidos em tourinhos zebuínos.

\begin{tabular}{lcccc}
\hline Sistema & \multicolumn{3}{c}{ GPD $\left(\mathrm{kg} \mathrm{dia}^{-1}\right)$} & Número de \\
\cline { 2 - 4 } & Mínimo & Médio & Máximo & observação \\
\hline Observado & 0,59 & 0,92 & 1,66 & 44 \\
Predito BR-CORTE & 0,72 & 1,45 & 2,56 & 44 \\
Predito CNCPS & 0,65 & 1,14 & 1,87 & 44 \\
Predito NRC & 0,65 & 1,20 & 2,08 & 44 \\
\hline
\end{tabular}

\section{Conclusões}

1. Os sistemas BR-CORTE, CNCPS 5.0 e NRC 2000 não se mostram adequados para predizer o desempenho de tourinhos zebuínos em confinamento.

2. Os diferentes grupos genéticos não apresentam diferenças no desempenho e nas características de carcaça quando submetidos ao regime de confinamento.

\section{Referências}

BERGEN, R.D.; MCKINNON, J.J.; CHRISTENSEN, D.A.; KOHLE, N.; BERLANGER, A. Prediction of lean yield in yearling bulls using real-time ultrasound. Canadian Journal of Animal Science, v.76, p.305-311, 1996.

BLOCK, H.C.; KLOPFENSTEIN, T.J.; ERICKSON, G.E. Evaluation of average daily gain prediction by level one of the 1996 National Research Council beef model and development of net energy adjusters. Journal of Animal Science, v.84, p.866-876, 2006.

FOX, D.G.; TYLUTKI, T.P.; TEDESCHI, L.O.; VAN AMBURGH, M.E.; CHASE, L.E.; PELL, A.N.; OVERTON, T.R.; RUSSEL, J.B. The net carbohydrate and protein system for evaluating herd nutrition and nutrient excretion: model documentation. Ithaca: Cornell University, 2003. 202p.

GESUALDI JÚNIOR, A.; QUEIROZ, A.C. de; RESENDE, F.D. de; ALLEONI, G.F.; RAZOOK, A.G.; FIGUEIREDO, L.A. de; GESUALDI, A.C.L. de S.; DETMANN, E. Desempenho produtivo e eficiência bioeconômica de bovinos Nelore e Caracu selecionados para peso aos 378 dias de idade recebendo alimentação à vontade ou restrita. Revista Brasileira de Zootecnia, v.35, p.576-683, 2006.

GESUALDI JÚNIOR, A.; QUEIROZ, A.C. de; RESENDE, F.D. de; LANA, R. de P.; GESUALDI, A.C.L. de S.; ALLEONI, G.F.; DETMANN, E.; RAZOOK, A.G.; FIGUEIREDO, L.A. de. Validação dos sistemas VIÇOSA, CNCPS e NRC para formulação de dietas para bovinos Nelore e Caracu, não-castrados, selecionados em condições brasileiras. Revista Brasileira de Zootecnia, v.34, p.997-1005, 2005.

GREINER, S.P.; ROUSE, G.H.; WILSON, D.E.; CUNDIFF, L.V.; WHEELER, T.L. The relationship between ultrasound measurements and carcass fat thickness and longissimus muscle area in beef cattle. Journal of Animal Science, v.81, p.676-682, 2003.

JORGE, A.M.; FONTES, C.A.A.; FREITAS, J.A.; RODRIGUEZ, L.R.R.; QUEIROZ, A.C.; RESENDE, F.D. Ganho de peso e de carcaça, consumo e conversão alimentar de bovinos e bubalinos, abatidos em dois estádios de maturidade. Revista Brasileira de Zootecnia, v.26, p.806-812, 1997.

KOBAYASHI, K.; SALAM, M.U. Comparing simulated and measured values using mean squared deviation and its components. Agronomy Journal, v.92, p.345-352, 2000.

MARAIS, J.P. Use of markers. In: D'MELLO, J.P.F. Farm animal metabolism and nutrition. Edinburgh: $\mathrm{CAB}$ International, 2000. p.255-278.

NATIONAL RESEARCH COUNCIL. Nutrient requirements of beef cattle. $7^{\text {th }}$ ed. Washington: National Academy Press, 2000. 242p.

NATIONAL RESEARCH COUNCIL. Nutrient requirements of dairy cattle. $7^{\text {th }} \mathrm{ed}$. Washington: National Academy Press, 2001. 381p.

NiChOLsOn, M.J.; BUTTERWORTH, M.H. A guide to condition scoring of zebu cattle. Addis Ababa: International Livestock Centre for Africa, 1986. 29p.

PATTERSON, T.; KLOPFENSTEIN, T.J.; MILTON, T.; BRINK, D.R. Evaluation of the 1996 beef cattle NRC model predictions of intake and gain for calves fed low or medium energy density diets. Nebraska Beef Report, p.26-29, 2000. MP 73-A.

SAINZ, R.D.; BARIONI, L.G.; PAULINO, P.V.R.; VALADARES FILHO, S.C.; OLTJEN, J.W. Growth patterns of nelore vs. british beef cattle breeds assessed using a dynamic, mechanistic model of cattle growth and composition. In: KEBREAB, E.; DIJKSTRA, J.; BANNINK, A.; GERRITS, W.J.J.; FRANCE, J. (Org.). Nutrient digestion and utilization in farm animals: modelling approaches. $6^{\text {th }} \mathrm{ed}$. Cambridge: CAB International, 2006. v.1, p.160-170.

SALIBA, E.O. Uso de indicadores: passado, presente e futuro. In: TELECONFERÊNCIA SOBRE O USO DE INDICADORES EM NUTRIÇÃO ANIMAL, 1., 2005, Belo Horizonte. Anais. Belo Horizonte: UFMG, 2005. p.4-22.

SAS INSTITUTE. SAS/STAT 1999-2001 user's guide: statistics. Version 8. Cary: SAS Institute, 1999.

SILVA, D.J. da; QUEIROZ, A.C. de. Análise de alimentos: métodos químicos e biológicos. Viçosa: UFV, 2002. 235p.

SILVA, F.F. da; VALADARES FILHO, S. de C.; ÍTAVO, L.C.V.; VELOSO, C.M.; VALADARES, R.F.D.; CECON, P.R.; PAULINO, P.V.R.; MORAES, E.B.K. de. Composição corporal e requisitos energéticos e protéicos de bovinos Nelore, não-castrados, alimentados com rações 
contendo diferentes níveis de concentrado e proteína. Revista Brasileira de Zootecnia, v.31, p.503-513, 2002.

VALADARES FILHO, S. de C.; MORAES, E.H.B.K.; DETMANN, E. Perspectivas do uso de indicadores para estimar o consumo individual de bovinos alimentados em grupo. In: REUNIÃO ANUAL DA SOCIEDADE BRASILEIRA DE ZOOTECNIA, 43., 2006, João Pessoa. Anais. João Pessoa: Sociedade Brasileira de Zootecnia, 2006a. p.291-322.

VALADARES FILHO, S. de C.; PAULINO, P.V.R; MAGALHÃES, K.A. Exigências nutricionais de zebuínos e tabelas de composição de alimentos / BR-CORTE. Viçosa: UFV, 2006b. 142p.

VÉRAS, A.S.C.; VALADARES FILHO, S. de C.; SILVA, J.F.C. da; PAULINO, M.F.; CECON, P.R.; VALADARES, R.F.D.; FERREIRA, M. de A.; LEÃO, M.I.; VALADARES, R.F.D.; MORAES, E.H.B.K. de. Predição da composição corporal e dos requisitos de energia e proteína para ganho de peso de bovinos, não-castrados, alimentados com rações contendo diferentes níveis de concentrado. Revista Brasileira de Zootecnia, v.30, p.1127-1134, 2001.

Recebido em 17 de junho de 2009 e aprovado em 23 de novembro de 2009 